\title{
Diagnóstico do nível de amplitude do alcance de práticas de gestão do conhecimento: um surveyem escolas públicas
}

\author{
GioFiscorti Madacb Mestre em Gestão do Conhecimento, Universidade Estadual do Paraná (UNESPAR) - Brasil. \\ caiopisconti@gmail.com \\ AthurGalbetoBacelardaCuz Doutor em Economia, Centro Universitário de Maringá (UNICESUMAR) - Brasil. \\ Upia arthur.urpia@unicesumar.edu.br \\ LetíäFeig Dá Fomo Doutora em Educação Especial, Centro Universitário de Maringá (UNICESUM AR) - Brasil. lefleig@gmail.com
}

\begin{abstract}
RESUMO
As atividades de gestão escolar têm sido consideradas mais do que meros processos que ocorrem no âmbito administrativo de uma escola. A gestão no contexto escolar possui um componente pedagógico, e além disto, influencia na qualidade dos serviços educacionais e no nível de rendimento estudantil discente. A partir da compreensão que alguns dos problemas específicos da gestão escolar se referem às limitações no gerenciamento do conhecimento, este artigo possui como objetivo examinar o nível de amplitude do alcance das práticas de gestão do conhecimento $(\mathrm{GC})$ de processos organizacionais nas instituições educacionais públicas participantes do Programa de Excelência na Educação Básica, considerando possíveis implicações destas para o nível da gestão escolar. Esta é uma pesquisa descritiva e exploratória, de natureza quantitativa. Quanto ao procedimento técnico utilizou-se a metodologia de pesquisa survey. Quanto à amostra, cinquenta e dois gestores educacionais participaram da pesquisa. Para a análise de confiabilidade dos dados utilizou-se a estatística alfa de Cronbach e para a análise quantitativa utilizou-se a estatística descritiva. Os dados coletados por meio do instrumento de diagnóstico foram caracterizados com consistência muito boa, segundo o valor do alfa de Cronbach. Verificou-se a ocorrência, de maneira predominante, de baixos níveis de percepção quanto ao nível de amplitude do alcance para a maioria das práticas de GC. Este resultado constituise um fator preocupante para o contexto escolar pesquisado, pois a não utilização das práticas de GC em suas totais potencialidades pode causar limitações nas atividades de identificação, criação e compartilhamento de conhecimento no ambiente escolar.
\end{abstract}

Palavras-chave: Gestão do Conhecimento. Processos Organizacionais. Gestão Escolar Pública.

\section{Diagnosis of the level of amplitude of the reach of knowledge management practices: a survey in public schools}

\begin{abstract}
School management activities have been considered more than ordinary processes that occur within the administrative environment of a school. Management in the school context has a pedagogical component, and, in addition, it influences the quality of educational services and the level of students' student performance. Knowing that some of the specific problems of school management refer to limitations in knowledge management, this article aims to examine the reach range level of knowledge management (KM) practices of organizational processes in the public educational institutions participating in the Program of Excellence in Basic Education, considering their possible implications for the level of school management. This is a descriptive and exploratory research of a quantitative nature. As for the technical procedure, the survey methodology was used. As to the sample, fifty-two educational managers participated in the research. For the data reliability analysis, Cronbach's alpha statistic was used and the descriptive statistics were used for the quantitative analysis. It was obtained that the data collected through the diagnostic instrument were characterized with very good consistency, according to the value of the Cronbach's alpha. There was a predominant occurrence of low levels of perception regarding the range of reach for most KM practices. This result is a worrying factor for the studied school context, since the non-use of KM practices in their total potentialities can cause limitations in the activities of identification, creation and knowledge sharing in the school environment.
\end{abstract}

Keywords: Knowledge management. Organizational Processes. Public School Management. 


\section{INTRODUÇÃO}

Para considerável parte dos estudos sob o contexto educacional no Brasil, realizados por estimados autores deste campo do conhecimento, dentre eles: Leão (1945), Castro (2000), Wittmann (2000), Lück (2000), Souza (2007), Menezes Filho (2006), Lourenço Filho (2007), Libâneo (2007), Drabach e Mousquer (2009), Paro (2010), Coelho (2011), Carvalho (2012) e Sander (2012), retratam de maneira específica, em um período considerável de tempo, a temática relacionada à administração e à gestão escolar.

Para a área de estudos que se refere à educação, o tema gestão escolar torna-se carregado de importância e complexidade quando se tem a compreensão de que a administração no contexto da educação é intrínseca à própria prática educativa, e se constitui uma dimensão da mesma (WITTMANN, 2000).

Sobre este enfoque, considera-se que as práticas e ações de organização e gestão escolar são componentes educativos, pois influenciam no processo de ensino-aprendizagem e na qualidade, como atividades desta natureza ocorrem no ambiente escolar. As práticas de gestão podem dizer respeito a ações de natureza técnico-administrativa e de natureza pedagógico-curricular (LIBÂNEO, 2007).

Diante disto, discute-se sobre a existência de um efeito-gestão presente nas escolas brasileiras. Este fenômeno é relacionado aos impactos gerados pelos dirigentes escolares e pelos processos de gestão no desempenho estudantil (SOUZA, 2007). Isto tem sido debatido quando se faz referência à ineficiência em termos de gestão, e obtenção de resultados educacionais, pois a qualidade dos serviços educacionais prestados e a eficiência com que as escolas operam são influenciadas pela forma como os processos de gestão são tratados nestes ambientes (DAMACENO, 2013; SOUZA, 2007; COELHO, 2011; CASTRO, 2000).

Nesta perspectiva, Carvalho (2008) analisa que o fracasso escolar aparece como resultado do mau gerenciamento destas instituições, da forte organização burocrática, centralizadora e do desperdício de recursos e de tempo (CARVALHO, 2012).

Assim, quando se verifica o contexto em que as escolas públicas brasileiras estão inseridas, percebese que há uma incoerência relacionada ao seu modelo de gestão. Ressalta-se isto, pois, as escolas, sendo organizações ricas em capital intelectual (representado por seus discentes, docentes, funcionários e membros da comunidade), não estão sendo geridas como organizações do conhecimento que pertencem a uma sociedade do conhecimento, fazendo contraposição à sua própria natureza e ao próprio ambiente do qual fazem parte (MACHADO; URPIA; FORNO, 2017b; MACHADO, 2017).

Por consequência, este fenômeno pode gerar limitações no rendimento estudantil e nos processos de ensino-aprendizagem. Assim, considera-se que a problemática relacionada à gestão escolar no Brasil é um assunto relevante que tem sido discutido e, além disto, se constitui em um problema amplo, complexo e recorrente encontrado na educação.

Neste sentido, torna-se necessário um enfoque e tratamento específico de acordo com a natureza destas limitações, que neste estudo, ocorreu por meio da perspectiva da gestão do conhecimento (GC) direcionada ao contexto escolar. Considera-se isto, pois, alguns dos problemas e limitações na gestão das escolas dizem respeito a especificamente problemas na gestão do capital intelectual, portanto, referem-se à área da GC (SANTOS; PAULA, 2012; SANTOS, 2008; MACHADO; URPIA; FORNO, 2017b; MACHADO, 2017).

Logo, a GC pode colaborar, por intermédio de práticas de processos organizacionais, para promoção e efetividade do compartilhamento de conhecimentos, aplicação de conhecimentos, criatividade e inovação nas organizações escolares (DAMACENO, 2013; MACHADO, 2017).

Tomando estes argumentos como base para discussão, questiona-se: em quais sentidos a GC, especificamente na perspectiva de processos organizacionais, auxilia na resolução do problema referente à gestão das escolas públicas? Diante disso, busca-se como objetivo para esta pesquisa examinar o nível de amplitude do alcance das práticas de GC de processos organizacionais nas instituições educacionais públicas participantes do Programa de Excelência na Educação Básica (PEEB), considerando possíveis implicações para o nível da gestão escolar.

O presente artigo, além desta introdução, contém mais quatro seções. Na segunda seção encontra-se o referencial teórico. Na terceira seção é apresentada a metodologia utilizada no estudo. A quarta seção constitui-se na apresentação de resultados e a quinta e última seção refere-se às considerações finais. 


\section{EFEITO-GESTÃO E A GESTÃO DO CONHECIMENTO NO CONTEXTO ESCOLAR}

Admite-se que as formas de organização e administração educativas no Brasil foram substancialmente influenciadas pelo modelo da administração científica, pautado em uma estrutura organizacional vertical, centralizadora e hierarquizada. Em decorrência da inviabilidade deste modelo de gestão, para o contexto das escolas, foram propostas políticas educacionais no Brasil, principalmente as adotadas a partir da segunda metade dos anos 1990, com o propósito de impulsionar mudanças na forma de organização e gestão da educação e da escola, rumo a uma gestão mais participativa (CARVALHO, 2012). Entretanto, verifica-se que estas peculiaridades referentes à dinâmica da gestão escolar ainda remetem grandes desafios à área educacional.

Neste sentido, entende-se, a partir das descrições apresentadas por Sander (1996), que a tradicional administração tecnoburocrática, de orientação funcionalista, não supera os problemas adjacentes à área, pois nem ao menos resolve os problemas básicos relacionados à gestão destas instituições.

Afere-se que este fator pode afetar a dimensão qualitativa dos serviços educacionais prestados aos discentes (MACHADO, 2017) e, além disto, o modelo de gestão anteriormente predominante institucionalizado nas escolas públicas não é coerente com o modelo requerido no contexto da sociedade do conhecimento.

Com o passar dos anos, tornou-se visível o surgimento de políticas públicas com o objetivo de inserir princípios democráticos, de autonomia e de construção coletiva, no cerne do processo de gestão e organização escolar (DRABACH; MOUSQUER, 2009), a fim de melhorar a gestão escolar.

No entanto, esta importante conquista se revelou insuficiente diante da realidade da educação brasileira, pois há um déficit educacional acumulado historicamente. Esta realidade sinaliza a necessidade de outras conquistas referentes ao campo educacional (SANDER, 2012), principalmente no que se diz respeito à inovação dos modelos de gestão destas organizações.

Portanto, uma das importantes conquistas que o campo da gestão escolar ainda tende a agenciar é a questão da excelência, relacionada aos processos, a organização e à gestão das escolas públicas. Diz-se isto, pois baseado nos achados referentes à tese de Souza (2007), evidencia-se a existência de certas proeminências que sinalizam uma relação entre o rendimento estudantil e os aspectos referentes à gestão das escolas. Verifica-se, deste modo, haver um efeito-gestão nas escolas brasileiras.

Isto porque as formas de organizações e de gestão podem desempenhar um papel educativo, já que fornecem certa informação às atitudes, às ideias e aos modos de agir, tanto para os docentes como para os discentes. Assim, torna-se razoável concluir que as escolas precisam ser melhor organizadas e geridas com vistas a promover a qualidade da aprendizagem escolar dos alunos (LIBÂNEO, 2007).

Desta forma, não se nega que as práticas pedagógicas são consideradas fatores relevantes na explicação do nível de qualidade do ensino prestado aos alunos e do nível de rendimento estudantil destes. Entretanto, a partir deste entendimento, passa a se considerar que, inclusive, os processos organizacionais de uma escola podem influenciar direta ou indiretamente o nível de qualidade do ensino prestado aos seus discentes, e também o rendimento estudantil destes (MACHADO, 2017).

Considera-se, assim, que há instrumentos e mecanismos da área da gestão que somados ao esforço aplicado através da criação e implementação de políticas públicas no campo da gestão educacional, podem auxiliar na redução deste déficit relacionado à qualidade e desempenho escolar dos discentes. Como possível resposta a alguns destes problemas, verifica-se que, através de métodos de gestão postulados na perspectiva da GC, torna-se possível o alcance de melhores níveis de qualidade no ensino (DAMACENO, 2013).

A reflexão acerca do conhecimento e da GC na educação aborda tanto a problemática referente à geração do conhecimento, em situações de ensino-aprendizagem, quanto é referente às estratégias de gestão escolar baseadas no conhecimento, a qual especificamente este trabalho se refere (RODRIGUES et al., 2010). Neste âmbito, definem-se algumas variáveis, com as quais se trabalha conjuntamente, para fazer frente aos complexos problemas da gestão escolar, que são: gestão escolar, GC e educação. 
Sabendo disto, examina-se à existência de alguns problemas específicos a GC que ocorrem no ambiente escolar, como por exemplo (MARCELO, 2009; HARGREAVES, 2003; BIRD; LITTLE, 1986; CARVALHO, 2012; LÜCK, 2000):

i) Falta de preocupação referente à integração de docentes no ensino;

ii) a carreira docente ser entendida como um trajeto individual, pouco ligado ao desenvolvimento de atividades coletivas;

iii) o isolamento dos professores ser claramente favorecido pela arquitetura escolar, que concebe as escolas em módulos padrão, ampliando este fator pelo modo como a distribuição do tempo e espaço são feitos;

iv) existência de uma cultura de independência e privacidade;

v) falta de habitualidade em desenvolver trabalhos conjuntos de docentes e discentes;

vi) falta de habitualidade em observar as atividades desenvolvidas pelos outros docentes, o que limita os meios para compartilhamentos de experiência;

vii) docentes que não têm hábitos de compartilhar e receber informação, por isto ampliam a deficiência no requisito de compartilhar conhecimentos;

vii) limitação de meios para armazenamento e transmissão de conhecimentos aos docentes em início de carreira; e

ix) estrutura administrativa vertical, centralizadora e hierarquizada.

Constata-se que existem proeminências que fazem convergir os temas de pesquisa. Afere-se, deste modo, a existência de constatação empírica quanto a GC auxiliar no desenvolvimento de competências dos docentes e discentes promovendo a participação e interação (CHU; WANG; YUEN, 2011; PETRIDES; NODINE, 2003).

Somado a isto, entende-se que vários dos problemas organizacionais das escolas estão diretamente ligados ao problema do conhecimento, no que diz respeito ao seu gerenciamento.

\subsection{Práticas de gestão do conhecimento como sugestão para melhoria da gestão escolar}

Verifica-se que, por meio de técnicas de gestão, na perspectiva da GC, torna-se possível o alcance de melhores condições de qualidade no ensino para promoção e efetividade do compartilhamento de conhecimentos, aplicação de conhecimentos, criatividade e inovação, para que melhorias na qualidade do ensino possam ser efetuadas (DAMACENO, 2013).

Acredita-se que as abordagens contemporâneas de gestão, como é o caso da GC - considerada uma eficiente abordagem para que o fluxo de conhecimentos na escola seja ágil e apoie o cumprimento das atividades de gestão - possam contribuir para a correta consecução das funções e processos administrativos da escola (MACHADO, 2017).

Estas práticas de GC estão dispostas aos gestores como orientadoras e direcionadoras a respeito de uma hipótese do "como fazer", podendo ser incorporados pelas organizações públicas sem alterar os seus padrões estruturais.

Assim, na sequência, estão especificados os achados de uma revisão bibliográfica, que contemplam as perspectivas parciais do que se tem estudado em relação ao tema: práticas de processos organizacionais em GC, ressaltando que estas possuem ampla aplicabilidade em organizações públicas, uma vez que foram elencadas com base nesse critério. 
Tabela 1 - Práticas de processos organizacionais em GC

\begin{tabular}{|c|c|}
\hline Práticas & Descrição \\
\hline $\begin{array}{l}\text { Mapeamento do } \\
\text { Conhecimento }\end{array}$ & $\begin{array}{l}\text { Codificação, por meio de taxonomias ou de mapas de conhecimento. Permite } \\
\text { identificar os ativos e as fontes de conhecimentos tácitos ou explícitos, mas não } \\
\text { os contém. Serve para localização, avaliação das capacidades, oportunidades } \\
\text { necessidades e restrições de conhecimentos. }\end{array}$ \\
\hline $\begin{array}{l}\text { Banco de } \\
\text { Competências } \\
\text { Individuais }\end{array}$ & $\begin{array}{l}\text { Repositório de informações que especifica em profundidade as competências } \\
\text { humanas: conhecimentos, habilidades e atitudes, no contexto organizacional. }\end{array}$ \\
\hline $\begin{array}{l}\text { Banco de } \\
\text { Competências } \\
\text { Organizacionais }\end{array}$ & $\begin{array}{l}\text { Repositório de informações que especifica em profundidade as competências } \\
\text { organizacionais que atuam mediante o trabalho em equipe nas organizações }\end{array}$ \\
\hline $\begin{array}{l}\text { Sistema de Gestão por } \\
\text { Competências }\end{array}$ & $\begin{array}{l}\text { Possui orientação no sentido de avaliar as competências internas, determinar } \\
\text { quais competências essenciais necessárias e definir estratégias para superar as } \\
\text { deficiências de competências identificadas comparativamente, no nível } \\
\text { individual e organizacional. }\end{array}$ \\
\hline $\begin{array}{l}\text { Gestão do Capital } \\
\text { Intelectual }\end{array}$ & $\begin{array}{l}\text { Gestão dos ativos humano, estrutural e de relacionamento com vistas a renovar, } \\
\text { organizar, avaliar, proteger e aumentar a disponibilidade dos ativos que } \\
\text { representam os conhecimentos presentes no âmbito organizacional. }\end{array}$ \\
\hline $\begin{array}{c}\text { Sistema de } \\
\text { Inteligência } \\
\text { Organizacional }\end{array}$ & $\begin{array}{l}\text { Transformação de informações em inteligência. Inclui a extração do } \\
\text { conhecimento a partir desta, como forma de apoiar os gestores na tomada de } \\
\text { decisão. }\end{array}$ \\
\hline Benchmarking & $\begin{array}{l}\text { Busca sistemática das melhores referências para comparação, com fins de } \\
\text { assimilação de processos, práticas, produtos ou serviços, em um esforço para } \\
\text { aumentar a produtividade, qualidade e desempenho organizacional. }\end{array}$ \\
\hline Melhores Práticas & $\begin{array}{l}\text { Metodologia ou abordagem para identificação, seleção e difusão práticas } \\
\text { inovadoras, know-how confiável e processos que garantam melhor desempenho } \\
\text { organizacional. }\end{array}$ \\
\hline $\begin{array}{c}\text { Memória } \\
\text { Organizacional }\end{array}$ & $\begin{array}{l}\text { Registro do conhecimento organizacional explícito em repositórios, sobre } \\
\text { processos, produtos, serviços e relacionamento com os stakeholders, envolvendo } \\
\text { recursos de gestão de conteúdo e mecanismos de consulta e recuperação. Deve } \\
\text { acontecer de forma colaborativa. }\end{array}$ \\
\hline
\end{tabular}

Fonte: Elaborado a partir de: Young (2009), American Productivity And Quality Centre (2018), Batista (2012), Araújo Júnior e Martins (2014), Carbone et al. (2009), Davenport e Prusak (1998) Driessen et al. (2007), Edvinsson e Malone (2003), Freire e Spanhol (2014), Lee e Fink (2013), Machado, Urpia e Forno (2017a), Massa e Testa (2004) Perrin et al. (2007), Purcidonio (2008), Stewart (1998) e Wiig (2000).

Ressalta-se que por meio de práticas e ações de GC se torna possível o alcance de: melhores índices de qualidade no ensino prestado aos discentes (DAMACENO, 2013), maiores índices de acerto nas tomadas de decisão, em situações de incerteza; maiores subsídios e formas de apoio ao corpo docente no cumprimento de seus objetivos; desenvolvimento e maior aproveitamento do capital intelectual disponível na organização e na comunidade escolar; alcance de melhores níveis de eficiência na gestão das organizações escolares (MACHADO, 2017); e aumento do nível de capacidade de realização do indivíduo, das equipes de trabalho e própria organização pública (BATISTA, 2012).

Desta forma, vislumbra-se a possibilidade do alcance de melhores níveis de eficiência na gestão das instituições públicas escolares e, como possível decorrência, de melhores níveis de rendimento estudantil, através da implementação destes planos formais da GC. Sob este mesmo aspecto, entende-se que o estágio de maturidade para a GC pode ser ampliado através da implementação de práticas e ações da GC. 


\section{METODOLOGIA}

Nesta seção, apresenta-se a metodologia utilizada para o desenvolvimento desta pesquisa. A pesquisa constitui-se em descritiva, pois observa, registra, analisa e correlaciona fenômenos (variáveis) ou fatos sem manipulá-los (CERVO; BERVIAN, 2002) e exploratória, por buscar levantar informações sobre um determinado objeto, delimitando assim um campo de trabalho, mapeando as condições de manifestação desse objeto (SEVERINO, 2017).

Quanto à natureza, é quantitativa. Nesta, o pesquisador irá traduzir em números as opiniões e informações para classificá-las e analisá-las. Esta abordagem requer o uso de recursos e de técnicas estatísticas (PRODANOV; FREITAS, 2013).

Quanto ao procedimento técnico, adotou-se o método de pesquisa survey, tendo em vista que o estudo possui o propósito de identificar a percepção dos gestores acerca do nível de amplitude das práticas de GC de processos organizacionais em escolas públicas. Na perspectiva acadêmica, a pesquisa survey possui como principais funções a descrição e a exploração (LIMA, 2016; PARANHOS et al., 2013).

As implicações derivativas dos resultados referem-se aos dados coletados dos gestores das escolas públicas participantes do PEEB. O PEEB é um programa desenvolvido pela UniCesumar desde 2013, que tem por objetivo principal assessorar escolas em sua prática docente com o intuito de melhorar os processos de ensino-aprendizagem e de gestão escolar (CASSIANO et al., 2015).

$\mathrm{Na}$ pesquisa apresentada por meio deste estudo, participaram os gestores que atuam, especificamente, no ambiente escolar público de nível fundamental, a saber: os diretores e os coordenadores pedagógicos. No total, cinquenta e dois gestores educacionais participaram da pesquisa, sendo vinte e três diretores de escolas e vinte e nove coordenadores escolares. A fim de manter o sigilo das informações, os gestores não serão identificados.

Estes gestores são representantes de escolas de quatorze municípios, a saber: Amaporâ, Floraí, Itaguajé, Jaguapitã, Marilena, Nossa Senhora das Graças, Nova Esperança, Presidente Castelo Branco, Querência do Norte, Santa Cruz do Monte Castelo, Santa Fé, São J orge do Ivaí, São Pedro do Paraná e Sarandi.

A amostra foi constituída a partir da participação dos gestores em um seminário promovido por meio de uma parceria entre a UniCesumar Empresarial, que coordena o PEEB, e o Programa de Pós-Graduação em Gestão do Conhecimento nas organizações da UniCesumar (PPGGCO). Desta forma, o tipo de amostragem utilizada foi a por conveniência (PRODANOV; FREITAS, 2013). 0 seminário teve também como objetivo capacitar os gestores das escolas a respeito do tema de GC e, mais especificamente, so bre as práticas de GC.

0 instrumento de coleta de dados utilizado foi o questionário desenvolvido pelo Instituto de Pesquisa Econômica Aplicada (IPEA). Houve uma adaptação no instrumento de diagnóstico para que este fosse aplicado aos gestores. Este instrumento de diagnóstico foi validado em estudos anteriores: Batista (2006) e Batista et al. (2005).

Este questionário se refere a uma lista com vinte e sete práticas de GC que "(...) foi elaborada a partir de exemplos concretos observados em organizações de todo o mundo, englobando aplicações práticas, técnicas, processos e ferramentas" (BATISTA, 2006, p. 12). Seguindo a classificação utilizada por Batista (2006; 2012), as práticas e ações contidas no questionário podem ser agrupadas em três catego rias: i) práticas e ações relacionadas principalmente aos aspectos de gestão de recursos humanos; ii) práticas e ações ligadas à estruturação dos processos organizacionais; e iii) práticas e ações cujo foco central é a base tecnológica e funcional.

Neste artigo são apresentadas as práticas relacionadas à segunda categoria descrita anteriormente, que se refere às práticas e ações ligadas à estruturação dos processos organizacionais. Estas práticas e ações funcionam como facilitadores da geração, retenção, organização e disseminação do conhecimento organizacional (BATISTA, 2006; BATISTA 2012)

Para a apresentação dos dados relativos ao nível do alcance das práticas pesquisadas, a seguinte escala foi utilizada: [1]: iniciativas isoladas dentro da organização; [2]: alguns departamentos usam a prática; [3]: muitos departamentos usam a prática; e [4]: amplamente disseminada na organização. 
No tocante ao nível de amplitude do alcance das práticas selecionadas, foram analisadas também apenas as respostas relacionadas aos níveis 3 (muitos departamentos usam a prática) e 4 (amplamente disseminada na organização) da escala do estágio de alcance, isso face ao fato de que apenas as respostas desses dois níveis indicam que as práticas analisadas possuem um alcance amplo.

Tabela 2 - Escala para análise dos resultados relativos ao nível de amplitude do alcance das práticas de GC

\begin{tabular}{cc}
\hline Nível de amplitude do alcance & Estágios 3+4 \\
\hline Nível baixo & Entre 0 a 39\% \\
Nível médio & Entre $40 \%$ a $60 \%$ \\
Nível alto & Acima de $60 \%$ \\
\hline
\end{tabular}

Fonte: Elaboração dos autores (2018).

Para a análise dos resultados coletados pelo questionário, uma abordagem quantitativa foi aplicada. Os resultados foram apurados por meio de técnicas de estatística descritiva, tais como análise de distribuição de frequência absoluta e relativa dos dados. A organização dos dados e o cálculo das estatísticas foram efetuados por meio do Programa Microsoft Excel (2010).

Para a análise de confiabilidade dos dados obtidos pelo questionário, utilizou-se a estatística alfa de Cronbach. 0 Coeficiente alfa de Cronbach é uma medida de confiabilidade comumente utilizada como uma estimativa de correlação entre duas amostras aleatórias de itens de um determinado universo (MATTHIENSEN, 2011; CRONBACH, 1951). 0 alfa é considerado um índice apropriado de equivalência, exceto para testes muito curtos (CRONBACH, 1951), como não é o caso deste estudo.

Hora, Monteiro e Arica (2010) definem que este cálculo refere-se à correlação média entre perguntas. Obtém-se o coeficiente a (alpha) por meio do cálculo da variância dos itens individuais e do cálculo da variância da soma dos itens de cada avaliador. Em seguida, pode-se verificar a equação para o cálculo do coeficiente alfa:

$$
\alpha=\left(\frac{k}{k-1}\right) \times\left(1-\frac{\sum_{i=1}^{k} s_{i}^{2}}{s_{t}^{2}}\right)
$$

Com relação aos elementos da equação, tem-se que: k: número de itens/perguntas do questionário; $s_{i}^{2}$ : variância de cada item; e $s_{t}^{2}$ : variância total do questionário, ou seja, a soma das variâncias dos avaliadores (MATTHIENSEN, 2011).

Tabela 3 - Qualificação da consistência, segundo o alfa de Cronbach

\begin{tabular}{cc}
\hline Intervalo & Consistência \\
$a<0,6$ & Fraca \\
$0,6 \leq a<0,7$ & Moderada \\
$0,7 \leq a<0,8$ & Boa \\
$0,8 \leq a<0,9$ & Muito boa \\
$a \geq 0,9$ & Excelente \\
\hline
\end{tabular}

Fonte: Adaptado de Loeschi e Hoeltgebaum (2012).

Para as ciências sociais e aplicadas, geralmente considera-se um alfa de 0,7 como um mínimo satisfatório. As seguintes regras podem ser seguidas para garantir as confiabilidades: i) para mensuração de um determinado conceito, o número de itens de uma escala deve ser igual ou superior a três e ii) se o 
coeficiente alfa for baixo, sugere-se que sejam removidos os itens de mensuração correlacionados com os outros com nível inferior a 0,3. 0 recálculo da confiabilidade pode aumentar o valor do alfa (LOESCH; HOELTGEBAUM, 2012). 0 método de purificação, que é caracterizado como: recálculo da confiabilidade é realizado através do recálculo

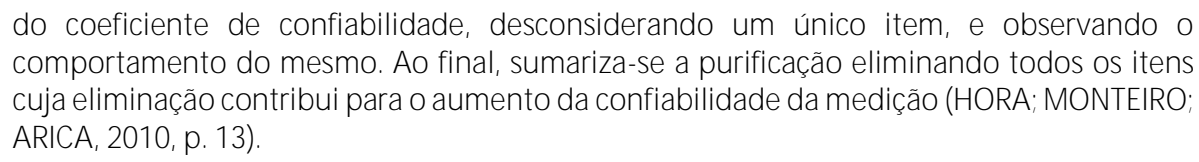

Desta, forma, para esta pesquisa o cálculo do alfa de Cronbach foi realizado por meio do programa Microsoft Excel (2010). Preferiu-se a utilização da planilha eletrônica ao invés dos pacotes estatísticos, tal como o SPSS, pelo motivo de acompanhamento do processo de cálculo e purificação da escala, assim como realizado por Hora, Monteiro e Arica (2010).

\section{APRESENTAÇÃO DOS DADOS E ANÁLISE DOS RESULTADOS}

Para análise de consistência dos dados do questionário, foi realizada a tabulação dos dados provenientes da pesquisa. Cada uma das nove práticas contidas no instrumento de diagnóstico do IPEA foi transformada em itens de uma planilha.

Foi realizada uma tabulação com as nove práticas que representam a categoria de processos organizacionais. Estas práticas são as seguintes: i) benchmarking interno e externo; ii) melhores práticas; iii) mapeamento do conhecimento; iv) sistema de gestão por competências; v) banco de competências individuais; vi) banco de competências organizacionais; vii) memória organizacional; viii) sistemas de inteligência organizacional; e ix) gestão do capital intelectual. Cada uma das práticas foi transformada em itens para o cálculo do alfa de Cronbach. Para os nove itens que representam o nível de alcance das práticas de GC de processos organizacionais, 0 alfa de Cronbach foi de 0,8299. Este valor representa um nível de consistência muito boa.

Diante do resultado encontrado, buscou-se o método de purificação da escala para verificar a possibilidade do aumento da confiabilidade da medição da escala. Sabendo que a análise de purificação da escala auxilia o pesquisador acerca da percep ção sobre a pertinência ou não de um item, em um determinado levantamento de dados (HORA; MONTEIRO;ARICA, 2010, p. 13), verifica-se na Tabela 4, os resultados referentes ao recálculo do coeficiente de alfa de Cronbach, ao se desconsiderar cada um dos nove itens pertencentes às práticas de GC de processos organizacionais.

Tabela 4 - Método de purificação da escala

\begin{tabular}{ccc}
\hline \multicolumn{3}{c}{ NÍVEL DE IMPLEMENTAÇÃO } \\
\hline \multicolumn{3}{c}{ OMISSÃO DE VARIÁVEIS } \\
\hline VARIÁVEL & VALOR DE ALFA \\
Q1 & 0,7965 & - \\
Q2 & 0,7950 & - \\
Q3 & 0,7911 & - \\
Q4 & 0,7854 & - \\
Q5 & 0,7915 & - \\
Q6 & 0,7889 & - \\
Q7 & 0,7887 & - \\
Q8 & 0,7826 & \\
Q9 & 0,8181 \\
\hline \multicolumn{4}{c}{ Fonte: Elaboração dos autores (2018). }
\end{tabular}


Assim, verifica-se através da Tabela 4 - Método de purificação da escala, que o valor do Alfa de Cronbach só seria ampliado caso fosse excluído o último item (Q9 - Gestão do Capital Intelectual), algo que faria com que o valor de alfa de Cronbach aumentasse para 0,8397.

Como, por meio desta possibilidade, o nível de consistência não seria significativamente alterado, ou seja, este não passaria de muito bom para excelente, optou-se por manter esta variável, dada a sua importância para o contexto pesquisado. Isso pode significar que as respostas decorrentes da aplicação do instrumento de diagnóstico possuem confiabilidade.

\subsection{Resultados da análise do diagnóstico}

Em seguida, estão relacionados os resultados do diagnóstico sobre o nível de percepção dos diretores e coordenado res pedagógicos acerca das práticas de GC de processos organizacionais no ambiente escolar.

Através da análise do nível de alcance será possível perceber o nível de influência que os planos, práticas ou ações de processos organizacionais possuem sob a instituição escolar, seus departamentos e planos de implementação dessas práticas (BATISTA et al., 2005).

$\mathrm{Na}$ Tabela 5 consta a distribuição de frequência relativa do nível de alcance das práticas de GC de processos organizacionais.

Tabela 5 - Nível de alcance das práticas de GC de processos organizacionais

\begin{tabular}{|c|c|c|c|c|c|}
\hline \multirow[b]{2}{*}{ ACÃO OU PRÁTICA } & \multicolumn{5}{|c|}{ ALCANCE } \\
\hline & 1 & 2 & 3 & 4 & $N / R$ \\
\hline Mapeamento do conhecimento & $35 \%$ & $15 \%$ & $17 \%$ & $25 \%$ & $8 \%$ \\
\hline Banco de competências individuais & $73 \%$ & $4 \%$ & $12 \%$ & $2 \%$ & $10 \%$ \\
\hline Banco de competências organizacionais & $54 \%$ & $6 \%$ & $13 \%$ & $17 \%$ & $10 \%$ \\
\hline Sistema de gestão por competência & $48 \%$ & $12 \%$ & $12 \%$ & $19 \%$ & $10 \%$ \\
\hline Benchmarking interno e externo & $25 \%$ & $33 \%$ & $19 \%$ & $15 \%$ & $8 \%$ \\
\hline Melhores práticas & $23 \%$ & $23 \%$ & $31 \%$ & $21 \%$ & $2 \%$ \\
\hline Gestão do capital intelectual & $46 \%$ & $6 \%$ & $12 \%$ & $17 \%$ & $19 \%$ \\
\hline Sistemas de inteligência organizacional & $42 \%$ & $19 \%$ & $10 \%$ & $13 \%$ & $15 \%$ \\
\hline Memória organizacional & $33 \%$ & $12 \%$ & $17 \%$ & $29 \%$ & $10 \%$ \\
\hline Médias & $42 \%$ & $14 \%$ & $16 \%$ & $18 \%$ & $10 \%$ \\
\hline
\end{tabular}

Com respeito à Tabela 5, verifica-se a ocorrência, de maneira predominante, de baixos níveis de percepção quanto ao nível de amplitude do alcance (soma dos níveis 3 e 4), para a maioria das práticas de GC de processos organizacionais abordadas no estudo. Dentre estas práticas, estão às seguintes: Benchmarking, Gestão do Capital Intelectual, Sistema de Inteligência Organizacional, Banco de Competências Individuais, Banco de Competências Organizacionais e Sistema de Gestão por Competências.

Este tipo de problema acaba por afetar a capacidade de realização: i) individual, dos funcionários da instituição; ii) das equipes, que formam e fazem parte da dinâmica escolar (colegiados, grupos discentes, associações etc.); e por fim, iii) de toda a comunidade, em que a escola está inserida (BATISTA, 2012).

Por isso, verifica-se que este é um fenômeno preocupante, pois as escolas que apresentam baixo nível de percepção acerca das práticas de GC podem apresentar problemas no desenvolvimento do capital humano dos docentes, discentes, funcionários da instituição e comunidade escolar.

De modo geral, constata-se que a predominância do nível de amplitude do alcance das práticas da gestão do conhecimento, abordadas no estudo, varia entre o nível baixo e médio. Isto possibilita deduzir que as práticas de gestão do conhecimento planejadas, em implementação ou presentes em departamentos e setores específicos destas organizações estudadas, ainda não estão influenciando ou causando um alto impacto, de acordo com suas capacidades de gerar resultados organizacionais. 
Acredita-se que é preciso uma análise pormenorizada para que sejam mais bem compreendidas as possíveis implicações que os resultados referentes ao nível de amplitude do alcance de cada prática podem trazer para o ambiente escolar público.

Assim, de acordo com a Tabela 5, segundo $73 \%$ dos gestores escolares a prática Banco de Competências Individuais encontra-se compreendida somente em iniciativas isoladas nestas instituições. Somente $2 \%$ dos gestores indicaram que a prática está disseminada e influenciando amplamente a organização e apenas $12 \%$ afirmaram que muitos departamentos utilizam esta prática. Com relação ao Banco de Competências Organizacionais, $60 \%$ dos gestores responderam que esta prática está circunscrita a iniciativas isoladas ou restrita a somente alguns departamentos da escola. Somente $17 \%$ dos gestores indicaram que 0 Banco de Competências Organizacionais encontra-se amplamente disseminado na organização.

Este resultado pode ser mais bem visto através do Figura 1, que retrata os níveis de amplitude do alcance de cada uma das práticas.

Figura 1 - Nível de amplitude do alcance das práticas de GC de processos organizacionais

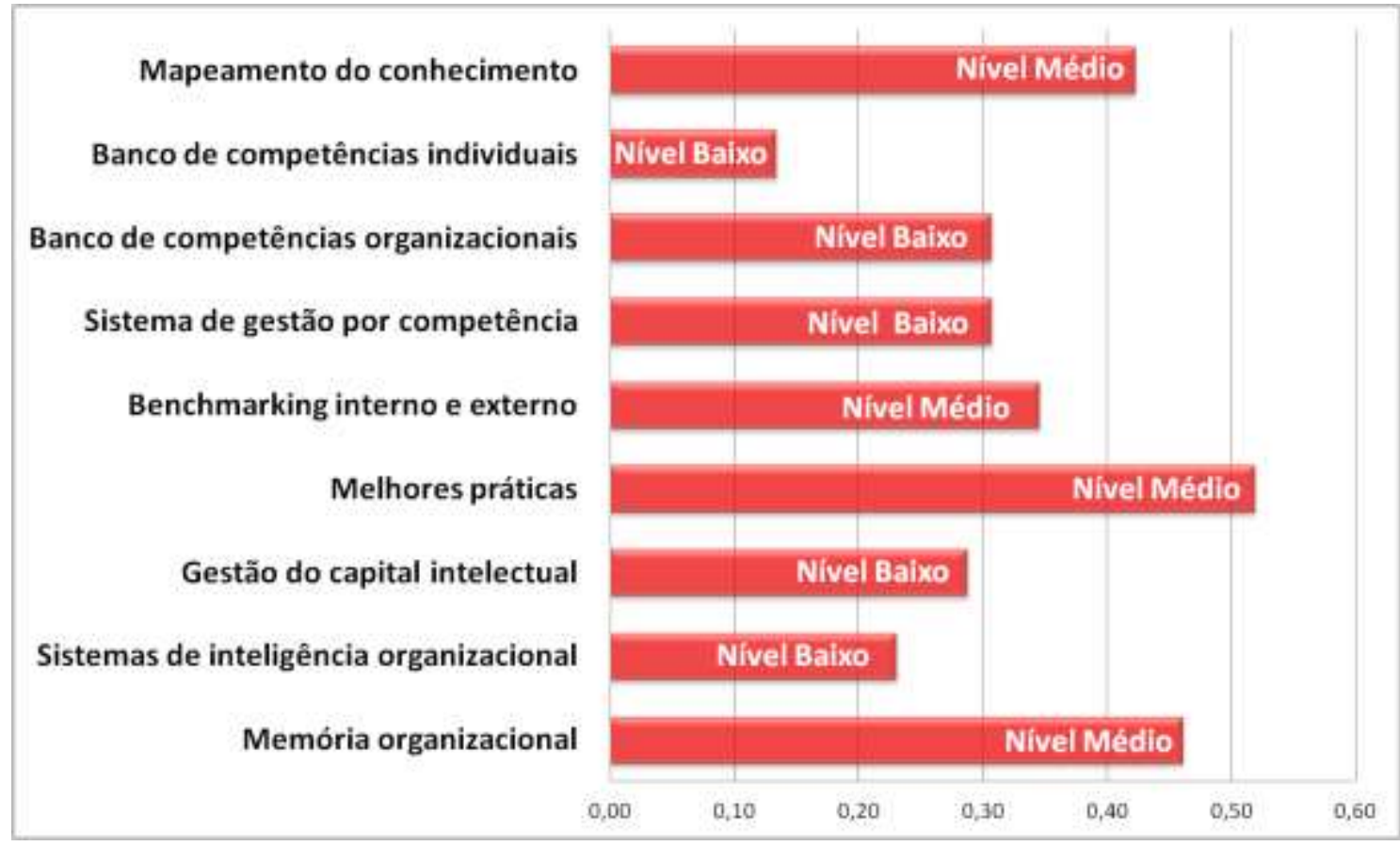

Fonte: Dados da pesquisa (2018).

Assim, observa-se pela Figura 1, que as práticas Banco de Competências Individuais e Banco de Competências Organizacionais possuem os menores níveis de amplitude do alcance, quando comparadas as demais práticas abordadas neste estudo.

Afere-se também que o resultado obtido com a prática Banco de Competências Individuais serve, de certa forma, para justificar o resultado encontrado para a prática Banco de Competências Organizacionais, já que esta última é composta por informações acerca das competências de cada um dos funcionários da organização.

Compreende-se que estes resultados podem trazer sérias implicações para as escolas que se encontram nesta situação, uma vez que esses tipos de práticas são amplamente utilizadas para informar os gestores sobre o que a organização dispõe em termos de competências intelectuais, além de auxiliar os gestores e funcionário em seus processos decisórios, tanto em decisões de nível simples, como em decisões de nível complexo, no que diz respeito à organização do ambiente escolar. 
Diante disto, o aproveitamento efetivo das competências presentes nos funcionários destas escolas pode estar sendo desperdiçado, o qual, por consequência, pode gerar um efeito limitador sob a qualidade e a maneira como os processos organizacionais são tratados nestas instituições.

Com relação à prática Sistema de Gestão por Competências, verifica-se, pela Tabela 5, que ela está situada em nível de amplitude do alcance baixo, já que apenas 19\% dos gestores perceberam esta prática amplamente disseminada em suas organizações e outros $60 \%$ perceberam-na compreendida em iniciativas isoladas ou em influenciando somente alguns departamentos de suas organizações.

Por meio de outros estudos, que retratam estas três práticas descritas até então, (MACHADO, 2017; MACHADO; URPIA; FORNO, 2017b), percebe-se a existência de uma possível relação conceitual entre as práticas Banco de Competências Individuais, Banco de Competências Organizacionais e a prática Sistema de Gestão por Competências, já que esta última recebe inputs daquelas outras práticas para sua concepção. Neste sentido, sugere-se que os baixos níveis de amplitude do alcance das práticas Banco de Competências Individuais e Banco de Competências Organizacionais estariam influenciando, em parte, o baixo nível de amplitude do alcance da prática Sistema de gestão por Competências.

Por meio desta análise, verifica-se que a ausência de um nível amplo de influência desta prática no ambiente organizacional destas escolas poderia acarretar problemas, tais como no aperfeiçoamento das competências e alinhamento destas aos interesses e competências requeridas pela escola no Planejamento Político Pedagógico (PPP).

Com relação à prática Benchmarking, verificou-se que está prática encontra-se amplamente disseminada nas organizações escolares para apenas $15 \%$ dos gestores, enquanto outros $58 \%$ dos gestores indicaram que suas atividades compreendem-se em iniciativas isoladas ou influenciando alguns departamentos de suas escolas. Devido a isto, o nível de amplitude do alcance para esta prática é considerado baixo.

Sugere-se que, como implicação derivada deste resultado, estas escolas não estão sendo influenciadas por melhores referências, no que diz respeito à execução de seus processos e serviços.

As práticas Gestão do Capital Intelectual e Sistema de Inteligência Organizacional também foram classificadas em nível de amplitude do alcance baixo, já que, respectivamente, para estas duas práticas, $52 \%$ e $61 \%$ dos gestores assinalaram que estas encontram-se compreendidas em iniciativas isoladas ou influenciando somente alguns departamentos de suas escolas. Apenas $17 \%$ dos gestores consideraram que a Gestão do Capital Intelectual está amplamente disseminada em suas organizações. De igual forma, somente outros 13\% verificaram que as atividades da prática Sistema de Gestão por Competências influenciam a organização de modo disseminado.

Dado que estas práticas possuem maior aderência a fatores cognitivos - de natureza tácita, afere-se que estes tipos de processos não estão sendo trabalhados de modo efetivo e podem gerar sérias limitações futuras ao nível da gestão destas instituições.

Com respeito aos resultados encontrados para a prática Gestão do Capital Intelectual, examina-se que estes também se constituem em uma questão preocupante, pois a partir deles sugere-se que os gestores não estão conseguindo verificar a influência dos próprios processos de desenvolvimento e integração de ativos intelectuais que ocorrem em suas organizações. Visto que a prática possui uma perspectiva de alcance ampla no ambiente escolar, estas escolas também podem possuir problemas de disponibilização e isolamento de conhecimentos e informações no nível institucional.

Já com relação à prática Sistema de Inteligência Organizacional, entende-se a partir dos resultados descritos na Tabela 5, que os gestores não estão utilizando, em suas totais potencialidades, dos processos de busca sistemática de informações, percepção e interpretação das realidades contingentes, para direcionar seus processos de tomadas de decisão. Isto pode gerar graves faltas de alinhamento e discrepância entre 0 ambiente interno e externo da escola, e se constituir em uma barreira para concepção de atividades e processos inovadores.

De forma geral, examina-se a existência de um efeito muito limitado das práticas Banco de Competências Individuais, Banco de Competências Organizacionais, Sistema de Gestão por Competências, 
Benchmarking, Gestão do Capital Intelectual e Sistema de Inteligência Organizacional sob os processos organizacionais, do âmbito administrativo das escolas pesquisadas.

Examina-se que isto pode constituir-se em um fator inibidor das atividades de identificação, criação e compartilhamento de conhecimento no ambiente escolar e por consequência limitar a capacidade de realização individual, das equipes e até mesmo da comunidade em que a escola está inserida. Como implicações gerais decorrentes disto, verifica-se a limitação no aperfeiçoamento dos processos e dos ativos intelectuais, e, consequentemente, a lentidão e falta de fluidez nos processos realizados no nível da gestão.

Com relação às práticas classificadas em nível de amplitude do alcance médio, nota-se que, especificamente o Mapeamento do Conhecimento - 0 qual 42\% dos gestores indicaram estar presente em muitos departamentos ou amplamente disseminada na organização, e a Memória Organizacional - a qual $46 \%$ dos gestores de igual forma fizeram a mesma aferição, são importantes práticas que apoiam os processos administrativos, contribuindo com as atividades de armazenamento e identificação de conhecimentos tácitos e explícitos.

O Mapeamento do Conhecimento, quando bem aplicado no ambiente escolar, pode auxiliar na resolução de alguns problemas básicos da escola, como aqueles relacionados aos fluxos de conhecimento (comunicação) e provisão de apoio aos gestores em seus processos de tomada de decisão, como por exemplo, onde estão localizados os detentores de conhecimento tácito e explícito dentro de suas escolas, quais os fluxos de conhecimento na organização, quais os setores que possuem mais fragilidades em relação a conhecimentos específicos.

A Memória Organizacional pode ser amplamente utilizada para evitar retrabalhos, especificamente nos processos de organização do ambiente escolar. Também pode auxiliar na realização de novos projetos, pois serve de suporte para a concepção destes, tomando o conteúdo armazenado durante a implementação de ações ou projetos de igual natureza e provendo importantes informações que dão a base para a estruturação destas ações.

No entanto, por mais que estas práticas proporcionem benefícios peculiares a estas organizações, observa-se que elas não estão sendo utilizadas em suas totais potencialidades, devido ao seu nível de amplitude do alcance ser mediano.

Por isto, sugere-se que caso persistam alguns problemas referentes à organização do ambiente escolar, como por exemplo, a alocação de indivíduos e equipes especialistas em determinadas competências e dificuldades na operacionalização de outras práticas de GC, o Mapeamento do Conhecimento é considerado uma das primeiras ações na implementação de ações desta natureza e a Memória Organizacional é uma importante prática que provê apoio à consecução de todas as práticas de GC.

Por fim, de acordo com a Tabela 5 e com o Figura 1, as Melhores Práticas, sobre a qual $42 \%$ dos gestores assinalaram estar presente em muitos departamentos da organização ou amplamente disseminada na organização, é a prática que possui o maior nível de amplitude do alcance.

As Melhores Práticas possuem interessantes contribuições para o ambiente escolar. Diz-se isto, pois, por meio da comparação de práticas e processos, poderão ser identificadas novas formas relacionadas ao know-how (como fazer) para o setor da gestão escolar, ou seja, formas validadas e testadas empiricamente, com graus de eficiência superiores as utilizadas até então. Entretanto, este resultado parece ser limitador diante da ampla aplicabilidade de práticas como esta, especificamente para o contexto escolar.

Sendo assim, para as práticas compreendidas em nível de amplitude médio, recomenda-se que os gestores intensifiquem as ações deste tipo, já que possuem potencial de gerar resultados organizacionais, no que diz respeito ao alcance de melhores níveis de eficiência na prestação de serviços escolares.

\section{CONSIDERAÇÕES FINAIS}

Para atender o objetivo geral de examinar o nível de alcance das práticas de GC de processos organizacionais nas instituições educacionais públicas participantes do PEEB, considerando possíveis implicações para o nível da gestão escolar, realizou-se um diagnóstico acerca do nível de alcance das práticas 
de GC em escolas públicas de quatorze municípios distintos, totalizando o número de cinquenta e dois gestores participantes da pesquisa.

A partir do diagnóstico efetuado junto aos diretores e coordenadores pedagógicos destas instituições, obteve-se que determinadas práticas pesquisadas apresentaram um nível de amplitude do alcance baixo, dentre elas: o Banco de Competências Individuais, Banco de Competências Organizacionais, Sistema de Gestão por Competências, Benchmarking, Gestão do Capital Intelectual e Sistema de Inteligência Organizacional.

Com relação às práticas classificadas em nível de amplitude do alcance médio, destacam-se as seguintes: Mapeamento do Conhecimento, Memória Organizacional e Melhores Práticas. Nenhuma das práticas foram classificadas como possuindo um alto nível de amplitude do alcance alto.

De maneira geral, examina-se que este resultado pode constituir-se em um fator preocupante para o contexto escolar pesquisado. Diz-se isto, pois a não utilização das práticas de GC em suas totais potencialidades pode limitar as atividades de identificação, criação e compartilhamento de conhecimento no ambiente escolar, e, por consequência, influir na capacidade de realização individual, das equipes e até mesmo da comunidade em que a escola está inserida.

Considerando a presença do efeito-gestão nas escolas públicas brasileiras, notou-se que o problema da gestão escolar é um ponto crítico a ser discutido, embora complexo e amplo.

Desta forma, não se pretendeu neste artigo resolver todos os problemas atinentes a esta área, mas sim, mapear a situação das escolas públicas envolvidas nesta pesquisa em relação às práticas de GC e sugerir possíveis implicações a partir do diagnóstico efetuado.

Como desdobramentos futuros desta pesquisa, observa-se a necessidade de propor formas ou modelos de maturidade de práticas em GC, de modo a aperfeiçoar os processos de gestão escolar, com vistas ao alcance de melhores níveis de rendimento estudantil.

\section{REFERÊNCIAS}

AMERICAN PRODUCTIVITY AND QUALITY CENTRE. Knowledge management glossary. [2018]. Disponível em: https://www.apqc.org/knowledge-base/download/320028. Acesso em: 11 set. 2018.

BATISTA, Fábio Ferreira et al. Gestão do conhecimento na administração pública. Brasília: Ipea, 2005. Disponível em: http://ipea.gov.br/agencia/images/stories/PDFs/TDs/td_1095.pdf. Acesso em: 05 dez. 2018.

BATISTA, Fábio Ferreira. 0 desafio da gestão do conhecimento nas áreas de administração e planejamento das instituições federais de ensino superior (IFES). Brasília: Ipea, 2006. Disponível em: http://www.ipea.gov.br/portal/images/stories/PDFs/TDs/td_1181.pdf. Acesso em: 05 dez. 2018.

BATISTA, Fábio Ferreira. Modelo de gestão do conhecimento para a administração pública brasileira: como implementar a gestão do conhecimento para produzir resultados em benefício do cidadão, Brasília: Ipea, 2012. Disponível em:

http://www.en.ipea.gov.br/agencia/images/stories/PDFs/livros/livros/livro_modelodegestao_vol01.pdf. Acesso em: 05 dez. 2018.

BIRD; Tom; LITTLE, J udith Warren. How schools organize the teaching occupation. The Elementary School Journal, v. 86, n. 4, p. 493-511, mar. 1986.

CARBONE, Pedro Paulo et al. Gestão por competências: gestão do conhecimento. 3. ed. Rio de Janeiro: Editora FGV, 2009 .

CARVALHO, Elma Júlia Gonçalves de. Gestão escolar: da centralização à descentralização. Cadernos de Pesquisa em Educação, v. 16, p. 33-53, jul./dez, 2012. 
CARVALHO, Elma Júlia Gonçalves de. Mudanças no mundo do trabalho e na gestão da educação. In: SEMINÁRIO DO TRABALHO, ECONOMIA E EDUCAÇÃO, 6., 2008, Marília. Atas do VI Seminário do Trabalho: trabalho, economia e educação. Marília: UNESP, 2008.

CASSIANO, Natália Daiane; BARBOSA, Magda de França; MACUCH, Regiane da Silva. Desenvolvendo competências empreendedoras no ensino superior: Potencializar e empoderar para transformar. In: PICANÇO, Fabiana Cristina de Azevedo; CARNEIRO, Reginaldo Aparecido; PERIOTTO; Tânia Regina Corredato (org.). Empreendedorismo sob a ótica da Interdisciplinaridade. Maringá: Cesumar, 2015. p. 10-24. Disponível em: https://www.unicesumar.edu.br/empresarial/wpcontent/uploads/sites/31/2015/12/empreendedorismo-sob-a-otica-da-interdisciplinaridade-vii.pdf. Acesso em: 05 dez. 2018.

CASTRO, Marta Luz Sisson de. Gestão da Escola Básica: conhecimento e reflexão sobre a prática cotidiana da diretora de escola municipal. Em Aberto, Brasília, v. 17, n. 72, p. 71-87, fev./jun. 2000.

CERVO, Amado Luiz; BERVIAN, Pedro A. Metodologia cientíifica. 5. ed. São Paulo: Pearson Pretice Hall, 2002.

CHU, Kai Wing, WANG, Minhong, YUEN, Allan HK. Implementing Knowledge Management in School Environment: Teachers' Perception. Knowledge Management \& E-Learning: An International Journal, v. 3, n. 2, p. 139-152, 2011.

COELHO, Adriano de Sales. Gestão escolar e inovação: novas tendências em gestão escolar a partir das teo rias de gestão da inovação. 2011. Tese (Doutorado em Educação) - Pontifícia Universidade Católica de São Paulo, São Paulo, 2011.

CRONBACH LJ . Coefficient Alpha and the internal structure of tests. Psychometrika, v. 16, n. 3, 297-334, 1951.

DAMACENO, Rosileide da S. Ambiência para gestão do conhecimento nas escolas públicas de

Taguatinga. 2013. Dissertação (Mestrado em Gestão do Conhecimento e Tecnologia da Informação) Universidade Católica de Brasília, Brasília, 2013.

DAVENPORT, Thomas H.; PRUSAK, Laurence. Conhecimento empresarial. 13. ed. Rio de J aneiro: Campus, 1998.

MENEZES FILHO, Naércio A. Os determinantes do desempenho escolar do Brasil. Quais as políticas educacionais que realmente funcionam? São Paulo: USP, 2006. Disponível em: http://www.sebh.ecn.br/seminario_4/arquivo1.pdf. Acesso em: 05 dez. 2018.

DRABACH, Neila Pedrotti; MOUSQUER, Maria Elizabete Londero. Dos primeiros escritos sobre administração escolar no Brasil aos escritos sobre gestão escolar: mudanças e continuidades. Currículo sem Fronteiras, v. 9, n. 2, p. 258-285, jul./dez, 2009.

DRIESSEN, Samuel; HUIJ SEN, Willem-Olaf; GROOTVELD, Marjan. A framework for evaluating knowledge mapping tools. Journal of Knowledge Management, v. 11, p. 109-117, 2007.

EDVINSSON, Leif; MALONE, Michael S. El capital intelectual: cómo identificar y calcular el valor inexplorado de los recursos intangibles de su empresa. Barcelona: Géstion, 2003. Disponível em:

https://books.google.com.br/books?id=OuR9pY3yAPQC\&printsec=frontcover\&dq=El+capital +intelectual: $+C$ $\%$ C3\%B3mo+identificar+y+calcular+el+valor+inexplorado+de+los+recursos+intangibles+de+su+empresa. \&hl=pt-PT\&sa=X\&ved =0ahUKEwj83vSdnYnfAhXJ I5AKHepTDEAQ6AEIKTAA\# \#=onepage\&q\&f=false. Acesso em: 05 dez. 2018.

FREIRE, P. S.; SPANHOL, F. J. Conhecimento organizacional: produto ou processo?. Perspectivas em Gestão \& Conhecimento, João Pessoa, v. 4, n. 1, p. 3 - 21, 2014. 
HARGREAVES, David H. Education epidemic: transforming secondary schools through innovation networks. London: Demos, 2003. Disponível em: https://www.demos.co.uk/files/educationepidemic.pdf. Acesso em: 05 dez. 2018.

HORA, H. R. M.; MONTEIRO, G. T. R.; ARICA, J. Confiabilidade em questionários para qualidade: um estudo com o coeficiente Alfa de Cronbach. Produto \& Produção, Porto Alegre, v. 11, n. 2, p. 85-103, 2010.

LEÃO, A. C. Introdução à administração escolar. São Paulo: Campainha Editora Nacional, 1945. Disponível em:

https://books.google.com.br/books?id=jU1FAAAAIAAJ \&q=LE\%C3\%830,+A.+C.+Introdu\%C3\%A7\%C3\%A30+ $\%$ C3\%A0+administra\%C3\%A7\%C3\%A30 +escolar.+S\%C3\%A30+Paulo:+Companhia+Editora+Nacional, +194 $5 . \& \mathrm{dq}=\mathrm{LE} \% \mathrm{C} 3 \% 830,+\mathrm{A} .+\mathrm{C}$. Introdu $\% \mathrm{C} 3 \% \mathrm{~A} 7 \% \mathrm{C} 3 \% \mathrm{~A} 30+\% \mathrm{C} 3 \% \mathrm{~A} 0+$ administra\%C3\%A 7\%C3\%A30 +escolar.+ S\%C3\%A30+Paulo:+Companhia+Editora+Nacional,+1945.\&hl=pt-

PT\&sa=X\&ved=0ahUKEwityPfCnYnfAhUFi5AKHRuYDbwQ6AEILjAB. Acesso em: 05 dez. 2018.

LEE, J oseph; FINK, Dieter. Knowledge mapping: encouragements and impediments to adoption. Journal of Knowledge Management, v. 17, n.1, p. 16-28, 2013.

LIBÂNEO, J osé Carlos. Educação escolar: políticas, estrutura e organização, 4. ed. São Paulo: Editora Cortez, 2007.

LIMA, Márcia. Introdução aos métodos quantitativos em Ciências Sociais. In: ABDAL, Alexandre; OLIVEIRA, Maria Carolina Vasconcelos; GHEZZI, Daniela Ribas; SANTOS JÚNIOR, J aime (org.). Métodos de pesquisa em Ciências Sociais: Bloco Qualitativo. São Paulo: SESC/CEBRAP. p. 10-31. Disponível em:

http://bibliotecavirtual.cebrap.org.br/arquivos/2017_E-BOOK\%20Sesc-

Cebrap \%20Metodos\%20e\%20tecnicas\%20em\%20 ĊS\%20-\%20Bloco\%20Quantitativo.pdf. Acesso em: 05 dez. 2018.

LOESCH, C.; HOELTGEBAUM, M. Métodos estatísticos multivariados. São Paulo: Saraiva, 2012.

LOURENÇO FILHO, Manoel Bergström. Organização e administração escolar: curso básico. 8. ed. Brasília: Instituto Nacional de Estudos e Pesquisas Educacionais Anísio Teixeira, 2007. Disponível em: http://portal.inep.gov.br/documents/186968/484703/Organiza\%C3\%A7\%C3\%A30+e+administra\%C3\%A7\% C3\%A3o+escolar+curso +b\%C3\%A1sico/eef1570e-91ed-48fb-92b8-b7c99cba03c0?version=1.3. Acesso em: 05 dez. 2018.

LÜCK, H. Gestão escolar e formação de gestores. Em aberto, Brasília, v. 17, n. 72, p. 1 - 195, fev./jun. 2000.

MACHADO, Caio Pisconti; URPIA, Arthur Gualberto Bacelar da Cruz; FORNO, Leticia Fleig Dal. Gestão do conhecimento no ensino público: uma agenda de pesquisa. Revista CESUMAR, Maringá, PR, v. 22, n. 1, p. 145-165, jan,/jun. 2017a.

MACHADO, Caio Pisconti; URPIA; Arthur Gualberto Bacelar da Cruz; FORNO, Leticia Fleig Dal. Roteiro de implementação de processos organizacionais em gestão do conhecimento para ensino público: uma agenda de pesquisa. In: ENCONTRO INTERNACIONAL DE PRODUÇÃO CIENTÍFICA, 10., 2017, Maringá. Atas do X EPCC. Maringá: UNICESUMAR, 2017b.

MACHADO; Caio Pisconti. Práticas de gestão do conhecimento de processos organizacionais no contexto escolar: proposta de um modelo teórico-conceitual. 2017. Dissertação (Mestrado em Gestão do Conhecimento nas Organizações) - Centro Universitário de Maringá, 2017.

MARCELO, Carlos. A identidade docente: constantes e desafios. Revista Brasileira de Pesquisa Sobre Formação Docente, Belo Horizonte, v. 1, n. 1, p. 109-131, ago./dez. 2009.

MASSA, Silvia; TESTA, Stefania. Innovation or imitation?: Benchmarking: a knowledge-management process to innovate services. Benchmarking: An International Journal, v. 11, p. 610-620, 2004. 
MATTHIENSEN, Alexandre. Uso do coeficiente Alfa de Cronbach em avaliações por questionários. Boa Vista: Embrapa Roraima, 2011. Disponível em:

https://www.infoteca.cnptia.embrapa.br/bitstream/doc/936813/1/DOC482011ID112.pdf. Acesso em: 05 dez. 2018.

PARANHOS, R. et al. Corra que o survey vem aí: noções básicas para cientistas sociais. Revista

Latinoamericana de Metodología de la Investigación Social, Buenos Aires, n. 6, p. 7-24, mar. 2013.

PARO, Vitor Henrique. A educação, a política e a administração: reflexões sobre a prática do diretor de escola. Educação e Pesquisa, São Paulo, v. 36, n. 3, p. 763 - 778, dez. 2010.

PERRIN, A.; ROLLAND, N.; Stanley, T. Achieving bestpractices transfer across countries. J ournal of Knowledge Management, v. 11, n. 3, p. 156 - 166, 2007.

PETRIDES, Lisa; NODINE, Thad. Knowledge management in education: Defining the Landscape. Half Moon Bay: Institute for the study of Knowledge Management in Education, 2003. Disponível em:

https://www.iskme.org/file?n=Knowledge-Management-in-Education-Defining-the-Landscape\&id=932. Acesso em: 05 dez. 2018.

PRODANOV, Cleber Cristiano; FREITAS; Ernani Cesar de. Metodologia do trabalho científico: métodos e técnicas da pesquisa e do trabalho acadêmico. 2. ed. Novo Amburgo: Feevale, 2013. Disponível em: http://www.feevale.br/Comum/midias/8807f05a-14d0-4d5b-blad-1538f3aef538/Ebook\%20Metodologia\%20do\%20Trabalho\%20Cientifico.pdf. Acesso em:05 dez. 2018.

PURCIDONIO, P. M. Práticas de gestão do conhecimento em arranjo produtivo local: o setor moveleiro de Arapongas - PR. 2008. Dissertação (Mestrado em Engenharia de Produção) - Universidade Tecnológica Federal do Paraná, Ponta Grossa, 2008.

RODRIGUES, Mônica Cairrão et al. Gestão do conhecimento e inovação. reflexões sobre o conhecimento na educação. RISUS - Revista de Inovação e Sustentabilidade, São Paulo, v. 1, n. 2, p. 1-14, 2010.

SANDER, Benno. A gestão da educação e o Plano Nacional de Educação. In: ENCONTRO ESTADUAL DE POLÍTICA E ADM INISTRAÇÃO DA EDUCAÇÃO/PE, 7., 2012, Pernambuco. Atas do VII Seminário Regional de Política e Administração da Educação do Nordeste. Pernambuco: ANPAE, 2012.

SANDER, Benno. Novas tendências na gestão da educação: democracia e qualidade. In: SIMPÓSIO REGIONAL DE ADMINISTRAÇÃO DA EDUCAÇÃO DO NORDESTE. GESTÃO E PARTICIPAÇÃO, 1., 1996, Fortaleza. Atas do Encontro Estadual de Política e Administração da Educação. Fortaleza: ANPAE/Ceará, 1996. p. 138 - 151.

SANTOS, Márcio J osé dos. Gestão do conhecimento: diagnóstico da gestão de uma escola pública da Região Noroeste do Estado de Minas Gerais. 2008. Dissertação (Mestrado) - Faculdades Pedro Leopoldo, Pedro Leopoldo, 2008.

SANTOS, Márcio J osé; PAULA, Claudio Paixão Anastácio de. Gestão do conhecimento no contexto da gestão escolar: estudo de caso de uma escola pública. Perspectivas em Gestão \& Conhecimento, João Pessoa, v. 2, p. 159-174, out. 2012. (Número Especial).

SEVERINO, Antônio Joaquim. Metodologia do trabalho científico. 24. ed. São Paulo: Cortez, 2017. Disponível em:

https://books.google.com.br/books?id=uBUpDgAAQBAJ \&printsec=frontcover\&dq=SEVERINO,+Antonio $+\mathrm{J}$ oa quim. +Metodologia+do+Trabalho+Cient\%C3\%ADfico.\&hl=pt-

PT\&sa=X\&ved=0ahUKEwjnxeaE0obfAhUCk5AKHRCeBV4Q6AEIKTAA\# $=0$ nepage\&q\&f=false. Acesso em: 05 dez. 2018.

SOUZA. Ângelo Ricardo de. Perfil da gestão escolar no Brasil. 2007. Tese (Doutorado em Educação) Pontifícia Universidade Católica de São Paulo, São Paulo, 2007. 
STEWART, Thomas A. Capital intelectual: a nova vantagem competitiva das empresas. 2. ed. Rio de Janeiro: Campus, 1998.

WITTMANN, L. C. Autonomia da escola e democratização de sua gestão: novas demandas para o gestor. Em Aberto, Brasília, v. 17, n. 72, p. 88-96, fev./jun. 2000.

YOUNG, Ronald. Knowledge management: tools and techniques manual. Tokyo: Asian Productivity Organization, 2010. Disponível em: http://www.apo-tokyo.org/publications/wp-content/uploads/sites/5/ind43-km_tt-2010.pdf. Acesso em: 17 set. 2018.

WIIG, Karl M. Application of knowledge management in Public Administration. [2000]. Disponível em: http://unpan1.un.org/intradoc/groups/public/documents/apcity/unpan020329.pdf. Acesso em: 17 set. 2018. 